\title{
Avaliação docente emancipatória: validação de uma ferramenta junto a docentes de Computação da UFPA.
}

\author{
Luiz Dourado Dias Junior ${ }^{1}$ \\ ${ }^{1}$ Instituto de Informática - Universidade Federal do Pará (UFPA) \\ Universidade Federal do Pará (UFPA) - Belém, PA - Brasil \\ \{ldourado1980@globo.com\}
}

\begin{abstract}
The teacher assessment is a tool for transformation of teaching. Discussion board tools have motivated research interest in this area, with proposals for teacher emancipatory evaluation using this type of tool. However, investigations are necessary to further user requirements. This article reports an experience of requirements validation, along with teachers in Computing Faculty at UFPA, identifying new needs, primarily for treatment of sharing ideas among teachers, favorable to emancipatory evaluation.
\end{abstract}

Key words: evaluation, teaching evaluation, on-line discussion boards, on-line discussion boards and evaluation.

Resumo. A avaliação docente é instrumento para transformação do trabalho docente. Ferramentas de fórum têm motivado interesse de pesquisa nesta área, havendo propostas de avaliação docente emancipatória com este tipo de ferramenta. Porém, são necessárias investigações que aprofundem os requisitos dos usuários. Este artigo relata uma experiência de validação de requisitos, junto a docentes da Faculdade de Computação da UFPA, identificando novas necessidades, principalmente, de tratamento do compartilhamento de reflexões entre os docentes, favoráveis ao estabelecimento da avaliação emancipatória.

Palavras chave: avaliação, avaliação docente, fóruns on-line, fóruns em avaliação.

\section{Introdução}

A temática da avaliação emancipatória, seja ela docente ou discente, começa certamente pela vinculação desta com uma determinada concepção educacional que a mesma deva avaliar. Seguindo-se nesta direção, cabe caracterizar uma concepção emancipatória de educação: esta se distingue, principalmente, por situar o ser humano como historicamente constituído e, justamente por isso, passível de reconstrução e transformação, principalmente, mediada pelo diálogo (FREIRE, 2005).

Conseqüentemente, o ser humano (na concepção emancipatória) é, extremamente, dotado de criatividade e autonomia. Neste sentido, uma avaliação emancipatória requer não apenas o diálogo, mas, essencialmente a criticidade, valorizando a criatividade e a autonomia dos participantes. Diálogo este que parte do princípio de que o ser humano é inacabado e precisa, para superar as limitações da sua realidade, perceber-se desta forma (idem). Na perspectiva freireana, o diálogo crítico move o ser humano a questionar a 
sua situação, fazendo-o buscar a superação de uma sociedade oprimida, para substituí-la por uma sociedade igualitária.

Neste contexto, emerge a seguinte questão: ao trazer a avaliação emancipatória para o contexto da avaliação docente, será que a mesma tem subsidiado tais ações avaliativas? Legalmente, o Sinaes (2009), o Inep (2009), dentre outros órgãos, estabelecem claramente uma avaliação de abrangência institucional, com bases qualitativas, formativas e também emancipatórias. Porém, ainda é realidade em instituições de ensino superior, a realização de avaliações definidas sem a participação dos professores e alunos, sem efetivo diálogo e, muitas vezes, fundada apenas em dimensões quantitativas (DEMO, 2005). Assim, a avaliação acaba assumindo uma conotação burocrática, sem significado real para os participantes destas realidades, pois a autonomia dos professores e alunos, bem como os problemas que vivenciam no cotidiano da sala de aula acabam não sendo valorizados, ainda que institucionalmente seja possível realizar avaliações estatisticamente representativas.

No sentido de uma concepção emancipatória, participativa e dialógica de avaliação, originalmente defendida pelo Sinaes (2009), pelo Inep (2009), bem como por autores como Freire (2005), Saul (2006) e Saviani (2004), há experiências tanto nacionais quanto internacionais que têm investido, especialmente, no uso de tecnologias de informação e comunicação (TIC) para apoiar este paradigma, no tocante à avaliação docente. Dentre estas experiências, podem ser destacadas: Kiper (1996) - uso de portfólios; Hagan (1997) - listas de discussão; Dias Junior \& Ferreira (2007) - uso de ferramentas de bate-papo; Bibby (2007) - uso de jornais elaborados pelos alunos; Dias Junior \& Ferreira (2008a) - ferramentas de fórum.

Considerando-se, porém, o diálogo como fundamental à transformação, então, ferramentas de fórum, listas de discussão e bate-papo deveriam caminhar para uma maior adequação, no que tange à avaliação docente. No entanto, apesar das pesquisas mencionadas inclusive proporem ferramentas na linha de fórum, com enfoque na avaliação docente, considera-se que ainda necessitem, principalmente, investigar com maior ênfase a visão de professores e alunos acerca do que vem sendo proposto, de modo a evoluir ou mesmo renegociar requisitos. Nesta linha, este trabalho relata uma experiência de validação dos requisitos propostos por Dias Junior \& Ferreira (2008b), junto a um grupo de professores do curso de Bacharelado em Ciência da Computação da Universidade Federal do Pará (UFPA).

Para atingir este objetivo, o trabalho está estruturado da seguinte forma: a seção 2 discute os aspectos teóricos do trabalho, focando o tema de avaliação emancipatória e uso de fóruns em avaliação docente; a seção 3 discute, sucintamente, a metodologia do trabalho; a seção 4 descreve os requisitos e o protótipo, originalmente proposto por Dias Junior \& Ferreira (2008b) para avaliação docente baseada em fóruns, e apresenta uma validação destes requisitos; a seção 5 propõe algumas reflexões finais e direciona perspectivas futuras para o trabalho.

\section{Aspectos teóricos}

A educação corresponde a um conjunto de ações intencionais que pretendem a promoção de determinados modelos de sociedade (SAVIANI, 2004). Em uma concepção emancipatória de educação, a sociedade é composta por homens e mulheres 
livres, autônomos, historicamente constituídos e condicionados (mas não determinados) pela liberdade do outro, bem como por características sociais, geográficas e políticas (idem).

Pelo fato de, constantemente, existirem atos, baseados no autoritarismo, que rumem na direção da negação destas liberdades, Freire (2005) afirma ser extremamente necessária uma concepção educacional emancipatória. Assim, este tipo de concepção vem, justamente, promover a libertação dos seres humanos, a comunhão e a cooperação entre eles, em meio ao diálogo, para a superação das problemáticas existentes (FREIRE, 2005).

Quando se desloca o foco de análise para a docência, a partir de uma concepção emancipatória, percebe-se, primeiramente, a característica do inacabamento do ser humano. Neste sentido, a docência como profissão não se encontra pronta e acabada, mas, em processo contínuo de reflexão e construção. Estas reflexões partem da análise das próprias práticas, para subsidiarem o questionamento e a transformação destas a partir da criticidade, autonomia e criatividade, pois, estas práticas, quando espontâneas, tendem a ser ingênuas (FREIRE, 2005).

Adicionalmente, as reflexões ocorrem em meio a um contexto social. Neste sentido, há, primariamente, a necessidade do diálogo como elemento de comunhão entre os sujeitos sociais (FREIRE, 2005). Nesta comunhão, o diálogo possui não só um caráter interativo, mas, revela também uma função diagnóstica, que favorece, justamente, problematizar a realidade, gradativamente, em um nível cada vez mais crítico (idem). Movimento este que, para Luckesi (1999), permite legitimar a avaliação desta realidade, pois, avaliar exige diagnóstico e intervenção para transformação.

Ainda que a reflexão seja um dos elementos desta problematização, a avaliação formalmente planejada e instituída é um mecanismo importante para promover a reflexão e, conseqüentemente, favorecer o aprimoramento das práticas docentes. Saul (2006) sistematiza um paradigma de avaliação para esta concepção de educação, baseado na pesquisa participante, na avaliação democrática e na crítica institucional. Referenciais estes que não só se aplicam as avaliações docentes em uma concepção emancipatória, mas, das próprias limitações e perspectivas de um programa educacional como um todo.

A avaliação emancipatória enfatiza a descrição, a análise e crítica de uma dada realidade, objetivando efetivamente transformá-la (SAUL, 2006). Sucintamente, este tipo de avaliação é realizado nos seguintes momentos: a) emancipação: a consciência crítica da situação e proposição de alternativas de solução; b) decisão democrática: envolvimento responsável e compartilhado dos elementos de um programa educacional; c) transformação: alterações substanciais derivadas coletivamente pelos indivíduos envolvidos; d) crítica educativa: análise valorativa do programa educacional, a partir da perspectiva dos participantes.

Fazendo-se uma leitura da avaliação emancipatória, percebem-se os seguintes elementos centrais para sua consecução: o engajamento, a participação e o diálogo. Considerando-se que o diálogo é instrumento primário de interação social, que propicia a participação, além de servir como mecanismo de engajamento e comprometimento entre os seres sociais, corrobora-se com Freire (2005) na percepção deste como elemento essencial.

No entanto, estabelecer o diálogo não tem sido trivial, especialmente, quando o tema é avaliação docente. Geralmente, esta dificuldade deriva de conflitos (entre 
professores, entre professores e alunos, dentre outros), existentes nas instituições de ensino, e que apresentam diversas naturezas (RIZO, 2005). Em muitos casos, este caráter não trivial de estabelecimento do diálogo pode ter origem em processos avaliativos autoritários, praticados em diversos momentos da história, marcadamente, com a caracterização do professor como responsável pelo fracasso educacional - o que renuncia completamente o caráter educativo da avaliação (idem).

Para abordar essa questão do estabelecimento do diálogo como elemento de transformação das práticas docentes, alguns trabalhos têm se utilizado das TIC, especialmente, sob uma perspectiva processual de avaliação docente. Dentre estas abordagens, destacam-se: a) Kiper (1996) - portfólios para avaliação docente; b) Hagan (1997) - o uso de listas de discussão com participação anônima; c) Bibby (2007) elaboração de jornais por parte dos alunos; d) Dias Junior \& Ferreira (2008a; 2008b) fóruns para apoiar a avaliação docente ao longo de disciplinas.

Os fóruns, em especial, têm se destacado nesta área de avaliação docente pelas seguintes características principais, segundo Clark (2003), Dimitracopolou (2005) e Dias Junior \& Ferreira (2008b): a) solução de problemas: propiciam ambientes de diálogo problematizador; b) flexibilidade de reflexão: maior tempo para reflexão e possibilidade de renegociação de significados (assincronismo); c) democratização: flexibilidade para participação com pessoas de diferentes com variados níveis de adaptação à tecnologia; d) externalização de pontos de vista: favorecerem a externalização de pontos de vista; e) comunidades virtuais: favorecerem a constituição de comunidades virtuais de aprendizagem. Cabe ressaltar que Dias Junior \& Ferreira (2008b) empregam e estudam a relevância destas características dos fóruns no contexto específico da avaliação docente, enquanto que os trabalhos dos primeiros autores se dedicam a aplicabilidade mais geral destas características.

\section{Aspectos metodológicos}

O estudo foi desenvolvido junto ao corpo docente da Faculdade de Computação da UFPA, composto por 23 professores. Embora uma solução em avaliação docente seja de interesse geral, os docentes da área de Computação foram selecionados, principalmente, pelos seguintes critérios: a) o projeto de pesquisa partiu da problematização da avaliação docente no contexto da referida faculdade; b) os docentes poderiam opinar como futuros usuários e, enquanto projetistas de interface - contribuição técnica.

O foco do estudo foi à validação de um protótipo de ferramenta de avaliação docente desenvolvido a partir dos requisitos, originalmente apresentados por Dias Junior \& Ferreira (2008b). A escolha deste trabalho base foi motivada por: a) ter sido realizado na mesma Faculdade; b) ter situado como trabalho futuro, a necessidade de construção e validação de protótipo, para aperfeiçoamento e refinamento dos requisitos.

Para proceder à validação, construiu-se um protótipo dos requisitos de Dias Junior \& Ferreira (2008b). Este protótipo foi construído em linguagem de programação Java, com o apoio do framework Java Server Faces (JSF) para desenvolvimento de aplicações web em padrão MVC (Model View Controller), e mecanismo de persistência baseado em arquivos XML (Extensible Markup Language). Apesar de a prototipagem recomendar o desenvolvimento de protótipos pouco funcionais, sob pena de possível descarte dos mesmos, construiu-se um funcional, principalmente por: a) possuir maior possibilidade de validação da interface proposta; b) antecipar a identificação de riscos técnicos de implementação, bem como a proposição de uma arquitetura. 
Concluído o desenvolvimento do protótipo, os professores da Faculdade de Computação foram convidados a participar de uma dinâmica com duração prevista de uma hora. A dinâmica previa a apresentação do protótipo ao professor e, em seguida, o uso deste para desempenhar as seguintes atividades: criação de uma reflexão, listagem, alteração, exclusão e compartilhamento. Ao longo desta dinâmica, o professor era estimulado, pelo pesquisador, a expressar opiniões favoráveis ou desfavoráveis acerca do protótipo, as quais eram registradas manualmente para posterior codificação e análise com apoio da Grounded Theory.

A Grounded Theory é uma metodologia de pesquisa qualitativa que defende a construção de uma teoria fundamentada em dados, sendo estes analisados e categorizados sistematicamente (STRAUSS \& CORBIN, 2008). Sinteticamente, o processo é constituído por: 1) codificação aberta: atribuição de rótulos/conceitos a segmentos de textos coletados; 2) codificação axial: relacionamento entre conceitos, agrupamento de conceitos em categorias e identificação de propriedades e dimensões; 3 ) codificação seletiva: identificação da categoria central do estudo. Os motivos de escolha desta neste estudo foram:

Esta metodologia foi escolhida por: 1) possibilidade de estudo de um fenômeno, a partir da visão dos envolvidos, o que é favorável ao campo de requisitos; 2) credibilidade junto à comunidade de Engenharia de Software (NETO \& GOMES \& OLIVEIRA, 2007). Em consonância com a metodologia, fez-se uma amostragem teórica, ou seja, sem estabelecimento prévio de tamanho. Este foi definido ao longo da pesquisa, até a percepção, apoiada na sensibilidade teórica, de que um novo caso não agregasse mais valor à teoria construída (saturação teórica) (STRAUSS \& CORBIN, 2008).

\section{Validação de uma ferramenta para avaliação docente baseada em fóruns}

Dias Junior \& Ferreira (2008b) consideram que os principais requisitos a serem atendidos por uma ferramenta de fórum em avaliação docente pertencem aos grupos: avaliação e reflexão. Para estes autores, é possível realizar uma avaliação docente emancipatória nos ambientes de fórum, desde que estes possibilitem a participação anônima facultativa, pois, esta facilita o estabelecimento do diálogo.

No que tange, porém, à reflexão sobre as práticas docentes, estes autores defendem que os fóruns, no estágio atual, são insuficientes para atender. Neste contexto, estes autores propõem uma ferramenta para, em conjunto com os fóruns, permitir: avaliar mensagens (sob a perspectiva da contribuição da mesma para o aprimoramento da prática docente), sumarizar discussões (resumir para facilitar a identificação de pontos favoráveis, desfavoráveis e sugestões), manter reflexões (cadastrar, alterar e excluir) e ainda comnartilhá-las com outros nrofessores (amnliacão do diálnono)

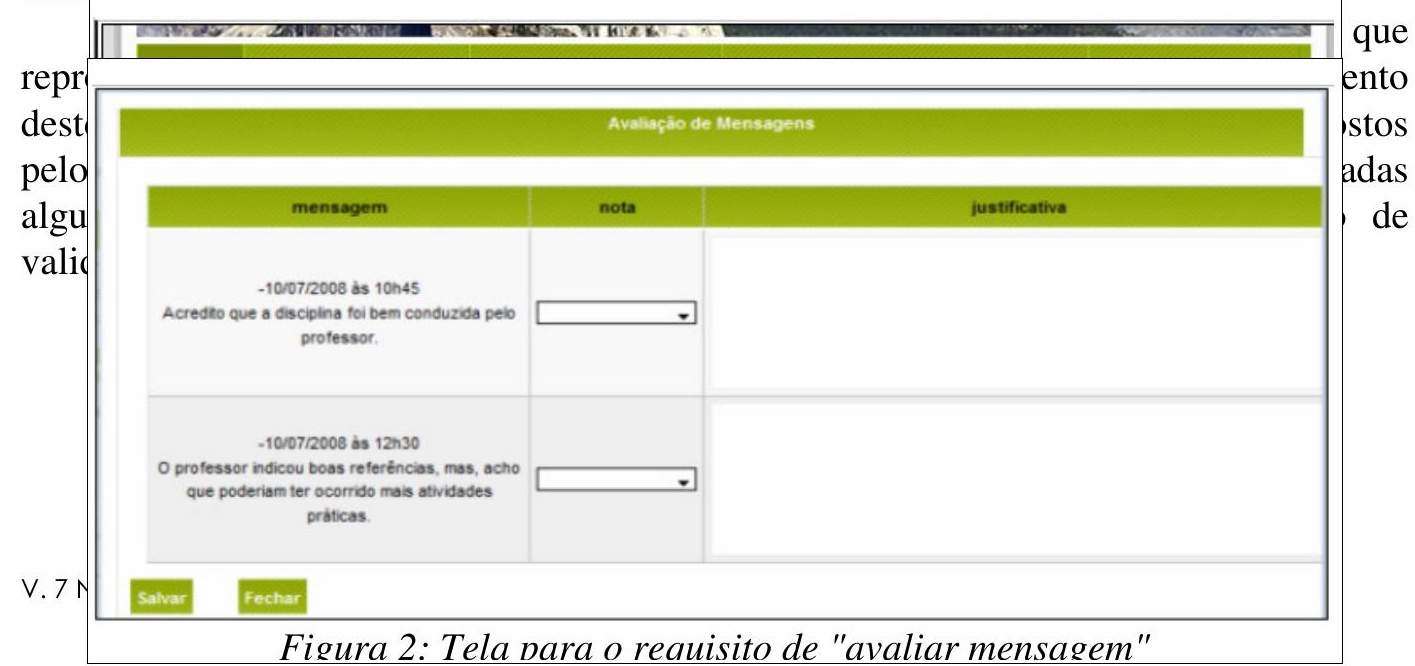


Depois de apresentar o protótipo aos professores e registrar em notas de campo as impressões, sugestões e críticas, estes foram codificados e categorizados, com apoio da Grounded Theory. Consequientemente, um conjunto de categorias e conceitos (derivados de segmentos das manifestações dos professores) foi produzido, tendo-se como categorias centrais: 1) requisitos não funcionais: agrupam observações relacionadas à portabilidade, eficiência, usabilidade, dentre outros; 2) requisitos funcionais: agrupam observações relacionadas às funcionalidades do protótipo.

Dentre as categorias de "requisitos não funcionais", destacam-se primeiramente: "compatibilização com Internet Explorer" e "redução da imagem". A primeira expressa um requisito de portabilidade, mostrando a necessidade de flexibilizar a operação do sistema em navegadores diferentes. A última (no que tange ao menu inicial do sistema) expressa um requisito de usabilidade, pois, no contexto coletado indicou um desconforto, o que pelo reduzido tempo de uso do protótipo, requer atenção de projeto. Outros aspectos de usabilidade foram manifestados, dentre eles a navegabilidade do sistema: "estratégia de habilitação" e subcategorias "por clique" e "habilitação quando necessário". As sugestões relacionadas ao editor de texto FCKEditor (2009) merecem destaque, para o que se apresenta o Quadro 1, com algumas evidências empíricas:

\begin{tabular}{|c|l|}
\hline \multicolumn{2}{|c|}{ Evidência } \\
\hline 1 & "Não mostrar editável a reflexão compartilhada..” \\
\hline 2 & $\begin{array}{l}\text { "Editores de texto: poderia ser apenas um único campo de edição com áreas pré-formatadas para inserção de } \\
\text { conteúdo - pontos favoráveis, etc." }\end{array}$ \\
\hline 3 & $\begin{array}{l}\text { "Não deve exibir os editors de texto na visualização da reflexão. A informação deve ser apresentada } \\
\text { "somente-leitura".” }\end{array}$ \\
\hline 4 & "Na visualização de reflexão compartilhada tirar a visualização em modo de edição." \\
\hline 5 & "Poderia ter um editor de texto mais simples." \\
\hline 6 & "Editar texto na visualização, não parece adequado (afinal se trata apenas de uma consulta).” \\
\hline 7 & "componentes de edição de texto - redundantes" \\
\hline
\end{tabular}

Quadro 1 - Evidências empíricas para a categoria "melhorias no editor de texto".

Primeiramente, no que tange a ação de visualizar uma reflexão compartilhada, as evidências (1), (3), (4) e (6) sugerem a retirada do componente de edição. As evidências (2), (5) e (7) indicam, possivelmente, preocupações com aspectos que prejudicam a usabilidade. Diante disto, percebe-se que o componente usado foi pouco satisfatório, podendo ser substituído por um editor mais simples, ou mesmo adequado no que tange às diversas opções que disponibiliza e que podem ter tornado confusa usabilidade.

No que tange aos requisitos funcionais, destaca-se o "compartilhamento de reflexões". Esta categoria expressa algumas necessidades já identificadas em Dias Junior \& Ferreira (2008b), mas, as expande quanto a seletividade. Detectou-se uma preocupação dos professores quanto ao fato do compartilhamento tornar públicas, para qualquer usuário do sistema, as práticas e problemas das disciplinas lecionadas. A preocupação com este tipo de exposição justificou a necessidade de escolha, pelos professores, dos usuários com os quais desejam compartilhar as reflexões. Algumas evidências de "compartilhamento de reflexões" são apresentadas no Quadro 2.

\begin{tabular}{|l|l|l|}
\hline Categoria & \multicolumn{2}{|c|}{ Evidência } \\
\hline Freqüência & 1 & $\begin{array}{l}\text { "O compartilhamento de reflexões entre os professores precisa ser permanente, para melhoria } \\
\text { efetiva." }\end{array}$ \\
\hline
\end{tabular}




\begin{tabular}{|l|l|l|}
\hline \multirow{2}{*}{ Abstração } & 1 & $\begin{array}{l}\text { "Se houvesse rodízio de professores, o compartilhamento seria mais útil para o aprimoramento das } \\
\text { disciplinas - hoje esse rodízio é raro." }\end{array}$ \\
\cline { 2 - 4 } & 2 & "O sistema poderia ser mais útil para compartilhar reflexões mais abstratas sobre as disciplinas" \\
\hline \multirow{2}{*}{ Seletividade } & 1 & "Medo da crítica por outros profissionais, usaria as reflexões para mim mesmo." \\
\cline { 2 - 4 } & 2 & "Compartilhamento mais seletivo, escolher com quem compartilhar." \\
\hline
\end{tabular}

Quadro 2 - Evidências empíricas para subcategorias de compartilhamento de reflexões.

Esta preocupação com a exposição pode estar relacionada, inclusive, com a questão dos processos avaliativos autoritários que, costumeiramente, responsabilizavam o professor pelos insucessos do processo educacional (RIZO, 2005). No entanto, as evidências do Quadro 2 mostram: a) no que tange à validação: este é um requisito relevante à avaliação docente emancipatória via fórum; b) quanto à avaliação docente de maneira mais ampla: há uma predisposição em compartilhar experiências, ainda que de maneira restrita, o que já é um aspecto favorável para a concepção emancipatória.

Outros requisitos funcionais relevantes são expressos pelas categorias: "comentar reflexões", "codificar mensagens", "filtrar comentários" e "integrar a outros sistemas". As evidências empíricas para estas categorias são apresentadas no Quadro 3 e discutidas nos parágrafos subseqüentes:

\begin{tabular}{|c|c|c|}
\hline Categoria & & Evidência \\
\hline \multirow{2}{*}{$\begin{array}{l}\text { Comentar } \\
\text { reflexões }\end{array}$} & 1 & "Permitir comentário acerca das reflexões." \\
\hline & 2 & $\begin{array}{l}\text { "Possibilidade de dar continuidade ao diálogo (por meio de comentários ou edição } \\
\text { colaborativa)." }\end{array}$ \\
\hline \multirow{3}{*}{$\begin{array}{l}\text { Codificar } \\
\text { mensagens }\end{array}$} & 1 & "Marcação de pós e contras de uma disciplina a partir de mensagens." \\
\hline & 2 & $\begin{array}{l}\text { "Quase uma possibilidade de codificação das mensagens (na hora de avaliar as mensagens - } \\
\text { códigos do tipo pontos favoráveis, sugestões identificadas, desfavoráveis).." }\end{array}$ \\
\hline & 3 & $\begin{array}{l}\text { "Quantificar quantas mensagens diferentes por códigos (interessante principalmente para } \\
\text { turmas grandes) - suposição." }\end{array}$ \\
\hline \multirow{3}{*}{$\begin{array}{c}\text { Filtrar } \\
\text { comentários }\end{array}$} & 1 & "É interessante ter alguma possibilidade de filtrar os comentários do aluno." \\
\hline & 2 & $\begin{array}{l}\text { "Filtrar mensagens = pode ter mensagens que não tenham nada a ver com o conteúdo } \\
\text { (possibilidade de descartar)" }\end{array}$ \\
\hline & 3 & $\begin{array}{l}\text { "Necessário haver equilíbrio entre o que o aluno pode preencher e o que o aluno vai } \\
\text { preencher (momento de coleta mais rígido)." }\end{array}$ \\
\hline \multirow{2}{*}{$\begin{array}{c}\text { Integrar a outros } \\
\text { sistemas }\end{array}$} & 1 & $\begin{array}{l}\text { "Dificuldades para utilização prática: falta de tempo/falta de integração com outros } \\
\text { ambientes." }\end{array}$ \\
\hline & 2 & "É necessário prover uma solução integrada." \\
\hline
\end{tabular}

Quadro 3 - Evidências empíricas comentar reflexões, codificar mensagens e filtrar comentários.

A partir dos trechos (1) e (2) da categoria "comentar reflexões", observa-se que alguns professores esperam que o protótipo forneça maiores possibilidades de diálogo. Estes trechos aliados com as categorias "compartilhamento das reflexões" e "comentar reflexões" expressam uma necessidade de expansão do diálogo. Esta necessidade é extremamente condizente com a comunhão pelo diálogo com fins de transformação, conforme defende Freire (2005). Além disto, estas necessidades no contexto da problematização das práticas docentes e do programa educacional mostram um cenário propício para a avaliação emancipatória de Saul (2006), favorecendo os momentos que a compõem: emancipação, decisão democrática, transformação e crítica educativa.

Os trechos (1), (2) e (3) da categoria "Codificar mensagens" exemplificam aspectos de outro requisito funcional. Percebe-se a partir destes trechos que, no 
protótipo apresentado, esta codificação não era feita de maneira explícita, ou seja, o usuário expressava pontos favoráveis, desfavoráveis e sugestões, mas, não os relacionava às mensagens que geravam esta classificação. Neste contexto, (1), (2) e (3) sugerem esta associação como um elemento facilitador ao processo de reflexão sistemática sobre as práticas docentes. Além disto, ao codificar as mensagens é possível extrair informações quantitativas por código (quantos alunos identificaram pontos favoráveis em uma disciplina, por exemplo), o que enriquece a abordagem qualitativa de avaliação e a combinação de abordagens.

No que se refere a "filtro de comentários", há uma preocupação com a relevância das mensagens. O protótipo atual trata esta questão com "filtros de mensagens" e "sumarização da discussão". No entanto, os trechos (1), (2) e (3) do Quadro 3 (referentes a "filtro de comentários") são relevantes, por se relacionarem ao momento do envio da mensagem do aluno no fórum, podendo minimizar a necessidade de o professor aplicar "filtros de mensagens" antes de sumarizar. A minimização desta necessidade acarreta, naturalmente, na diminuição do tempo dedicado pelo professor à análise, tornando o sistema mais atrativo ao uso. Neste contexto, encaixam-se os trechos (1) e (2) da categoria "Prover integração com outros sistemas".

\section{Considerações finais e trabalhos futuros}

Entende-se que este trabalho contribuiu, principalmente, com a problematização de uma proposta de avaliação docente baseada em fóruns, enriquecendo-a a partir de uma experiência de validação de requisitos. Conforme se pode avaliar, os requisitos identificados por Dias Junior \& Ferreira (2008b) apesar de relevantes, bem como a proposta de solução, precisavam de uma investigação maior e que favorecesse a aproximação de sua completude.

Certamente, há questões que precisam ser mais bem trabalhadas. Dentre elas, pode-se citar o fato de a validação ter ocorrido, inicialmente, com um público restrito de professores de Computação. Por ser um protótipo de interesse geral, não só para educação na referida área, faz-se necessário expandirem as experiências para aprofundar, ainda mais os requisitos, de modo que os mesmos possam abranger um público ainda maior de usuários. Apesar desta limitação, acredita-se ter sido possível coletar dados ricos e que permitem um redirecionamento relevante ao projeto de pesquisa, dentre eles na usabilidade - a visão mais técnica dos professores trouxe contribuições relevantes, em nível de projeto de interface o que, sem dúvida, é importante para um projeto de qualidade.

Por fim, cabe situar os achados deste trabalho no que tange à avaliação docente emancipatória baseada em fóruns. Conforme se discutiu, a avaliação necessita, principalmente, de uma comunhão pelo diálogo para diagnóstico e transformação de uma dada realidade. Neste sentido, o refinamento dos requisitos, apresentado por este trabalho, mostra que o grupo pesquisado pode estar caminhando em uma direção favorável a implementação de uma avaliação docente emancipatória, podendo ser favorecidos por uma solução computacional que os apóie tanto no momento de avaliar quanto de refletir sobre a avaliação. Assim, faz-se necessário evoluírem iniciativas nesta linha, bem como experimentações de uso destes tipos de ferramentas, para investigar em termos práticos o que pode e precisa ser aprimorado para o sucesso desta concepção transformadora de avaliação, valorizando-se as realidades docentes e discentes. 


\section{Referências}

BIBBY, P. Getting feedback: no pressure! In: Conference On Innovation And Technology In Computer Science Education, 11., Nova Iorque, EUA, 2006.

DEMO, P. Ser professor é cuidar que o aluno aprenda. $4^{\mathrm{a}}$ ed, Mediação, Porto Alegre, 2005.

DIAS Junior, L. D.; FERREIRA, B. de J. P. Dicotomia teoria-prática docente na educação superior: análise de ferramentas de fórum e proposta de conjunto de requisitos para apoiar reflexão sobre a prática. In: Revista Novas Tecnologias na Educação, UFRGS, Porto Alegre, vol 6, nº 1, 2008 a.

DIAS. Junior, L. D.; FERREIRA, B. de J. P. Avaliação docente dialógica: protótipo de ferramenta baseada em necessidades identificadas por professores de Computação da UFPA. In: Revista Hífen, PUC-RS, Uruguaiana, vol. 32, no 62, p. 51-58, 2008b.

DIMITRACOPOULOU, A. Designing collaborative learning systems: current trends \& future research agenda. Disponível em: http://portal.acm.org/citation.cfm?id=1149293.1149309 Acesso em: 20 dez. 2007.

FCKEditor. Disponível em: <http://www.fckeditor.net/> Acesso em: 10 fev. 2009.

FREIRE, P. Pedagogia do Oprimido. Paz e Terra, São Paulo, 2005.

HAGAN, D. Student feedback via World Wide Web. Disponível em: <http://ultibase.rmit.edu.au/Articles/june97/hagan1.htm> Acesso em: 18 jun. 2008.

INEP. Disponível em: <http://www.inep.gov.br/> Acesso em: 10 abr. 2009.

KIPER, J.D. Perspectives on assessment through teaching portfolios in computer science. SIGCSE Bull. 28, 1 (Mar. 1996), 200-203

LUCKESI, C. Avaliação da aprendizagem escolar. 9a ed., Cortez, São Paulo, 1999.

MORAES, R.; RAMOS, M. G. Avaliação do desempenho de professores numa perspectiva qualitativa: contribuições para o desenvolvimento profissional de professores universitários. In: Revista Iberoamericana de Educación, Madrid, ES, n. 108, p. 1-18, 2000.

NETO, G. C; GOMES, A.; OLIVEIRA, N. Aliando Grounded Theory e ReFormulações de Conceitos da Teoria da Atividade para o Melhor Entendimento de Práticas Humanas. In: Workshop on perspectives, challenges and opportunities for human-computer interaction in Latin America. Anais. Rio de Janeiro, 2007

RIZO, H. Avaliação do desempenho docente: tensões e tendências. In: Revista PRELAC, Universidade Autônoma de Occidente, Colômbia, 2005.

SAUL, A. M. Avaliação emancipatória: desafio à teoria e prática de avaliação e reformulação do currículo, Cortez, $7^{\mathrm{a}} \mathrm{Ed}$, São Paulo, 2006.

SAVIANI, D. Educação: do senso comum à consciência filosófica. $15^{\mathrm{a}}$ ed., Autores Associados, Campinas, 2004.

SINAES. Disponível em: <http://www.inep.gov.br/superior/SINAES/> Acesso em: 10 abr. 2009. 
STRAUSS, A.; CORBIN, J. (2008): Pesquisa qualitativa: técnicas e procedimentos para o desenvolvimento de teoria fundamentada. $2^{\mathrm{a}}$ ed., Porto Alegre: Artmed, 2008. 